\title{
FUZZY TIME SERIES MODEL CHENG UNTUK MERAMALKAN VOLUME HASIL PANEN PADA TANAMAN GARUT
}

\author{
Rifki Indra Perwira (1), Danang Yudhiantoro ${ }^{(2)}$, Endah Wahyurini (3) \\ 1 Jurusan Informatika, UPN "Veteran" Yogyakarta \\ 2Jurusan Manajemen, UPN "Veteran" Yogyakarta \\ 3Jurusan Agroteknologi, UPN "Veteran" Yogyakarta \\ e-mail : rifki@upnyk.ac.id(1), danangyudhiantoro@gmail.com ${ }^{(2)}$, endahwahyurini@yahoo.com ${ }^{(3)}$
}

\begin{abstract}
Arrowroot is an alternative food substitute that can be used as processed flour or starch. This arrowroot can also produce several processed products such as arrowroot chips. The number of arrowroot requests from various regions causes the need for accurate calculations related to the volume of harvest from the arrowroot. Fuzzy logic is a method that can be used to predict arrowroot yields every period to meet market demand. The parameters used in this system are based on environmental data (temperature humidity, climate, altitude), genetic data (age and variety), and cultivation technique data (seed quality, fertilizing, planting media). The results of this study are in the form of an application to predict the volume of arrowroot crop yields based on these parameters. From the results of MAPE, get a percentage of $11.7 \%$ which indicates that the level of accuracy using the fuzzy cheng time series model is said to be useful for forecasting on arrowroot plants.
\end{abstract}

\section{Keywords : Arrowroot, Fuzzy time series cheng, MAPE, Prediction}

Tanaman Garut merupakan alternative pengganti bahan pangan yang dapat dijadikan sebagai olahan tepung atau pati. Garut ini juga dapat menghasilkan beberapa produk olahan seperti emping garut. Banyaknya permintaan garut dari berbagai daerah menyebabkan perlu perhitungan akurat terkait volume hasil masa panen dari tanaman garut. Logika fuzzy merupakan sebuah metode yang dapat digunakan untuk memprediksi hasil panen garut setiap periodenya untuk memenuhi permintaan pasar. Parameter yang digunakan pada sistem ini berdasarkan data lingkungan (kelembaban suhu, iklim, ketinggian tempat), data genetic (umur dan varietas) dan data teknik budidaya (kualitas bibit, pemupukan, media tanam). Hasil penelitian ini adalah berupa aplikasi untuk memprediksi volume hasil panen tanaman garut berdasarkan parameter tersebut. Dari hasil MAPE mendapatkan prosentase sebesar $11,7 \%$ yang mengindikasikan bahwa tingkat akurasi menggunakan fuzzy time series model cheng dikatakan baik untuk melakukan peramalan pada tanaman garut.

Kata Kunci : Garut, Cheng fuzzy time series, MAPE, Prediksi

\section{PENDAHULUAN}

Tanaman Garut ini merupakan jenis herba, tegak, berumpun dan merupakan tanaman tahunan. Tinggi tanaman mencapai $0,5-1,5 \mathrm{~m}$, dengan batang berdaun dan mempunyai percabangan menggarpu. Selain sebagai sumber karbohidrat, rimpang garut juga memiliki manfaat kesehatan terutama bagi penderita diabetes atau penyakit kencing manis. Rimpang garut memiliki indeks glisemik yang lebih rendah (14) dibanding rimpang-rimpangan lainnya, seperti gembili (90), kimpul (95), ganyong (105), dan ubijalar (179). Rimpang garut berpotensi sebagai pangan lokal dan dapat diolah menjadi pati dan emping. Pati garut dapat dimanfaatkan sebagai bahan pengganti terigu dalam pengolahan pangan seperti kue, cake, roti (Djaafar et al. 2010) dan pasta ikan. Emping garut tidak mengandung kolesterol sehingga banyak disukai.

Banyaknya permintaan olahan tanaman garut menyebabkan UKM. Lancar Rejeki kesulitan untuk memenuhi karena keterbatasan umbi garut. Masa panen yang stabil dua tahun sekali tidak selalu menghasilkan volume umbi yang besar. Susilawati dan Endah (2018) telah meneliti tentang volume hasil panen satu periode menghasilkan umbi $60 \mathrm{~kg}$ dari bibit umbi dengan tiga mata tunas. Selama ini dalam memenuhi permintaan pasar sangat bergantung pada subjektifitas para petani garut (UKM. Lancar Rejeki). Dengan cara subjektif ini mengakibatkan banyak masalah, antara lain terjadi kekurangan stok umbi garut untuk memenuhi permintaan 
konsumen, banyak umbi yang ternyata rusak dan tidak bagus untuk pengolahan lebih lanjut, sedangkan disisi lain masa panen hanya satu tahun maksimal 2 periode sehingga stok umbi garut harus dihitung supaya cukup untuk untuk memenuhi kebutuhan pasar.

Fuzzy time series merupakan salah satu metode yang akurat dalam memprediksi. Chao (2004) pernah melakukan penelitian dengan topik memprediksi jumlah turis menggunakan time series. Mey dan Irawan (2014) juga pernah meneliti untuk memprediksi IHSG. Pada tahun 2015, Sandino dkk juga melakukan penelitian tentang prediksi penjualan.

Dari permasalahan diatas, UKM. Lancar Rejeki membutuhkan suatu aplikasi yang dapat memprediksi volume panen tanaman garut. Dalam makalah ini menggunakan acuan data-data panen periode sebelumnya untuk memprediksi hasil panen periode berikutnya. Pengujian akurasi fuzzy time series ini menggunakan Meas Absolute Percentage Error (MAPE) .

\section{METODE PENELITIAN}

\section{Observasi}

Makalah ini menggunakan data eksperimen yang diperoleh dari data-data hasil panen tanaman garut periode sebelumnya. Observasi dilakukan dengan melakukan pengamatan terhadap parameter-parameter yang berpengaruh terhadap pertumbuhan tanaman garut (Gardner, 1991).

\section{Wawancara}

Informasi yang diperoleh pada makalah ini dilakukan dengan cara wawancara. Wawancara dilakukan terhadap beberapa narasumber terkait pertanyaan-pertanyaan seputar garut dan budidayanya. Dalam penelitian ini, wawancara dilakukan kepada UKM. Lancar Rejeki.

1. Bu Roimah, selaku ketua UKM. Lancar Rejeki yang telah pengalaman dalam melakukan budidaya tanaman garut di desa kadireso menyatakan bahwa waktu panen garut sekitar bulan September - oktober. Karakteristik hasil panen garut setiap periode dapat berbeda tergantung cuaca.

2. Pak Suwardi, selaku petani garut yang telah berpengalaman melakukan budidaya dan teknologi hasil pertaniannya terhadap garut menyatakan selain cuaca, ada faktor kualitas bibit dan ph tanah.

\section{Metode Fuzzy Time Series Cheng}

Metode Cheng mempunyai cara yang sedikit berbeda dalam penentuan interval, menggunakan Fuzzy Logical Relationship (FLR) dengan memasukkan semua hubungan (all relationship) dan memberikan bobot berdasarkan pada urutan dan perulangan FLR yang sama. Berikut adalah tahapan-tahapan peramalan pada data time series dengan menggunakan FTS Cheng (Karasan, Sevim, \& Çinar, 2017)

Menentukan himpunan semesta $(U)$ data aktual, yaitu:

$\mathrm{U}=[\mathrm{Min}, \mathrm{Max}]$

di mana Min adalah data terkecil, Max adalah data terbesar

Penentuan lebar interval menggunakan distribusi frekuensi, dengan langkah-langkah sebagai berikut:

Menentukan rentang (range) dengan rumus sebagai berikut:

$R=$ Max - Min.

di mana adalah rentang Max adalah data terbesar Min adalah data terkecil.

Menentukan banyaknya interval kelas dengan menggunakan Persamaan Sturges. Adapun rumusnya sebagai berikut:

$K=1+3,3 \times \log (n)$

Menentukan lebar interval. Adapun rumusnya sebagai berikut:

$=\frac{\text { Range Data }(R)}{\text { Nilai Interval }(K)}$

Mencari nilai tengah, dengan rumus sebagai berikut:

$m_{i}=\frac{\text { (batas bawah +batas atas) }}{2}$

di mana i adalah banyaknya himpunan fuzzy. 
Mendefinisikan himpunan fuzzy, himpunan fuzzy $A_{1}, A_{2}, \ldots, A_{k}$ dapat dibentuk berdasarkan interval yang telah terbentuk sebelumnya. Untuk menyederhanakan, maka nilai keanggotaan dari himpunan fuzzy $A_{i}$ berada diantara $0,0.5,1$ dimana $1=\mathrm{i}=\mathrm{n}, \mathrm{n}$ adalah jumlah interval yang telah dibagi sebelumnya (Hayati \& Wahyuningsih, 2017).

Membuat table fuzzyfikasi dan fuzzy logic relationship (FLR) berdasarkan data aktual. FLR dapat dilambangkan oleh $A_{\tilde{i}} \rightarrow A_{\tilde{j}}$, di mana $A_{\tilde{i}}$ disebut current state dan $A_{j}$ disebut next state (Hayati \& Wahyuningsih, 2017).

Menentukan bobot relasi FLR menjadi Fuzzy Logical Relationship Group (FLRG) dengan memasukkan semua hubungan (all relationship) dan memberikan bobot berdasarkan pada urutan dan perulangan yang sama. FLR yang memiliki current state $\left(A_{\bar{i}}\right)$ yang sama digabungkan menjadi satu grup ke dalam bentuk matriks pembobotan. Misal terdapat suatu urutan FLR yang sama (Hayati \& Wahyuningsih, 2017).

$(\mathrm{t}=1) A_{1} \rightarrow A_{1}$, diberikan bobot 1

$(\mathrm{t}=2) A_{2} \rightarrow A_{1}$, diberikan bobot 1

( $\mathrm{t}=3) A_{1} \rightarrow A_{1}$, diberikan bobot 2

$(\mathrm{t}=4) A_{1} \rightarrow A_{1}$, diberikan bobot 3

( $\mathrm{t}=5) A_{2} \rightarrow A_{1}$, diberikan bobot 2

di mana menyatakan waktu. Kemudian bobot yang didapat pada relasi FLR dimasukkan ke dalam bentuk matriks pembobot $(\mathbf{W})$ yang persamaannya ditulis sebagai berikut:

$\mathrm{W}=\left[\begin{array}{cccc}w_{1} & w_{2} & \ldots & w_{1 p} \\ w_{2} & w_{2} & \cdots & w_{2} p \\ w_{p 1} & w_{p 2} & \cdots & w_{p}\end{array}\right]$

di mana $\mathrm{W}$ adalah matriks pembobot $w_{i}$ adalah bobot matriks pada baris ke- $\mathrm{i}$ dan kolom ke- $\mathrm{j}$ dengan $i=1,2, \ldots, p, j=1,2, \ldots, p$.

Kemudian mentransfer bobot FLRG tersebut ke dalam bentuk matriks pembobot terstandarisasi $\left(\mathrm{W}^{\star}\right)$ yang persamaannya ditulis sebagai berikut:

$\mathrm{W}=\left[\begin{array}{cccc}W_{1}{ }^{*} & w_{1}{ }^{*} & \ldots . & w_{1 p}{ }^{*} \\ w_{2}{ }^{*} & W_{2}{ }^{*} & \ldots & W_{2 p}{ }^{*} \\ W_{p 1}{ }^{*} & w_{p 2}{ }^{*} & \ldots & w_{p}{ }^{*}\end{array}\right]$

di mana $W^{*}$ adalah matriks pembobot terstandarisasi dengan $w_{i}^{*}=\frac{w_{i}^{*}}{\Sigma_{j-1}^{p} w_{i j}^{i}}$

Menentukan defuzzifikasi nilai peramalan. Untuk menghasilkan nilai peramalan, matriks pembobot terstandarisasi $\left(\mathrm{W}^{*}\right)$ dikalikan dengan $m_{i}$. Mencari nilai tengah $\left(m_{i}\right)$ pada interval himpunan fuzzy dapat menggunakan Persamaan matrika pembobotan terstandarisasi (Karasan et al., 2017). Sehingga perhitungan peramalannya menjadi:

$F_{1}=w_{1}^{*}\left(m_{1}\right)+w_{2}^{*}\left(m_{2}\right)+\ldots+w_{p}^{*}\left(m_{p}\right)$

Apabila hasil fuzzifikasi periode ke-i adalah $A_{i}$, dan $A_{i}$ tidak memiliki FLR pada FLRG dengan kondisi $A_{\tilde{i}} \rightarrow \emptyset$, di mana nilai maksimum derajat keanggotaannya berada pada $U_{\tilde{i}}$, maka nilai peramalan $\left(F_{i}\right)$ adalah nilai tengah dari $U_{i, \text { atau didefinisikan dengan }} m_{i}$. (Fahmi dkk, 2013)

Standar umum pengukuran kesalahan prediksi yang digunakan adalah Mean Square Error (MSE) untuk mengetahui tingkat kesalahan atau selisih nilai peramalan dengan nilai sebenarnya dengan hasil (+) atau (-) dan mean absolute error (MAE) hasil MSE yang diabsolutkan, dan mean absolute percentage error (MAPE) untuk persentase akurasi (Gustriansyah, 2017).

Nilai MAPE digunakan untuk menganalisis kinerja proses prediksi seperti yang tertera pada

Tabel 1. Nilai MAPE Untuk Evaluasi Prediksi

\begin{tabular}{|l|l|}
\hline Nilai MAPE & Akurasi Prediksi \\
\hline MAPE $\leq 10 \%$ & Tinggi \\
\hline $10 \%<$ MAPE $\leq 20 \%$ & Baik \\
\hline $20 \%<$ MAPE $\leq 50 \%$ & Reasonable \\
\hline MAPE $>50 \%$ & Rendah \\
\hline
\end{tabular}




\section{HASIL DAN PEMBAHASAN}

\section{Penerapan Logika Fuzzy Time Series Cheng Himpunan Semesta}

Setelah mendapatkan data hasil panen dalam beberapa bulan trakhir maka tahapan berikutnya mencari nilai data dengan nilai terkecil dan terbesar yaitu $(\operatorname{Max}=200$, Min $=112)$. Maka himpunan semesta yaitu sebagai berikut; $U=[112,200]$

\section{Mencari Panjang Interval}

Panjang interval menggunakan distribusi frekuensi memiliki langkah-langkah sebagai berikut:

Menghitung range, berdasarkan rumus 2 maka didapatkan range sebagai berikut:

$R=$ (Max - Min)

$R=(200-122)=88$

Menghitung nilai interval, berdasarkan rumus 3 maka didapatkan nilai interval sebagai berikut:

$\mathrm{K}=1+3,3 \times \log (\mathrm{n})$

$=1+3.3 \times \log (14)$

$=4.78$ dibulatkan menjadi 5

Menghitung lebar interval, berdasarkan rumus 4 maka didapatkan lebar interval sebagai berikut: $=\frac{\text { Range Data }(R)}{\text { Nilai Interval }(K)}$

Nis

$=\overline{5}=17.6$

Kemudian menentukan frekuensi setiap interval, frekuensi didapat dari jumlah data hasil panen yang terletak didalam masing-masing interval. Tabel berikut merupakan hasil frekuensi dan nilai tengah setiap frekuensi.

Tabel 2. Frekuensi Data dan Nilai Tengah

\begin{tabular}{|l|l|l|l|l|}
\hline Interval & Frekuensi & \multicolumn{2}{|c|}{ Nilai Tengah } & Kondisi \\
\hline$U_{1=(112,129.6)}$ & 2 & $m_{1}$ & 120.8 & Pertama \\
\hline$U_{2=(129.6,147,2)}$ & 3 & $m_{2}$ & 138.4 & Pertama \\
\hline$U_{3}(147.2,164.8)$ & 2 & $m_{3}$ & 156 & Pertama \\
\hline$U_{4=(164.8,182.4)}$ & 3 & $m_{4}$ & 173.6 & Pertama \\
\hline$U_{5}=(182.4,200)$ & 4 & $m_{5}$ & 191.2 & Pertama \\
\hline
\end{tabular}

\section{Fuzzyfikasi Data}

Fuzzyfikasi dapat terbentuk berdasarkan interval yang telah terbentuk sebelumnya, yaitu $A_{1}$ untuk interval $U_{1}$ dan seterusnya. Tabel berikut merupakan hasil fuzzyfikasi data.

Tabel 3. Fuzzyfikasi Data

\begin{tabular}{|l|l|l|l|}
\hline Periode & Hasil Panen $(\mathrm{Kg})$ & Fuzzyfikasi & Relasi \\
\hline 2014- kuartal 1 & 134 & $A_{2}$ & - \\
\hline 2014- kuartal 2 & 176 & $A_{4}$ & $A_{2} \rightarrow A_{4}$ \\
\hline 2015- kuartal 1 & 200 & $A_{5}$ & $A_{4} \rightarrow A_{5}$ \\
\hline 2015- kuartal 2 & 186 & $A_{5}$ & $A_{5} \rightarrow A_{5}$ \\
\hline 2016- kuartal 1 & 155 & $A_{3}$ & $A_{5} \rightarrow A_{3}$ \\
\hline 2016- kuartal 2 & 187 & $A_{5}$ & $A_{2} \rightarrow A_{5}$ \\
\hline 2017- kuartal 1 & 142 & $A_{2}$ & $A_{5} \rightarrow A_{2}$ \\
\hline 2017- kuartal 2 & 122 & $A_{1}$ & $A_{2} \rightarrow A_{1}$ \\
\hline 2018- kuartal 1 & 112 & $A_{1}$ & $A_{1} \rightarrow A_{1}$ \\
\hline 2018- kuartal 2 & 156 & $A_{3}$ & $A_{1} \rightarrow A_{3}$ \\
\hline 2019- kuartal 1 & 192 & $A_{5}$ & $A_{3} \rightarrow A_{5}$ \\
\hline 2019- kuartal 2 & 166 & $A_{4}$ & $A_{5} \rightarrow A_{4}$ \\
\hline & & &
\end{tabular}




\begin{tabular}{|l|l|l|l|}
\hline Periode & Hasil Panen (Kg) & Fuzzyfikasi & Relasi \\
\hline 2020- kuartal 1 & 143 & $A_{2}$ & $A_{4} \rightarrow A_{2}$ \\
\hline 2020- kuartal 2 & $\ldots \ldots$ & $\ldots$. & $\ldots \ldots$ \\
\hline
\end{tabular}

Tabel 4. Fuzzy Logic Relationship Group

\begin{tabular}{|l|l|}
\hline Group 1 & $A_{1} \rightarrow A_{1}, A_{1} \rightarrow A_{3}$ \\
\hline Group 2 & $A_{2} \rightarrow A_{1}, A_{2} \rightarrow A_{4}$ \\
\hline Group 3 & $A_{3} \rightarrow A_{5}$ \\
\hline Group 4 & $A_{4} \rightarrow A_{2}, A_{4} \rightarrow A_{5}$ \\
\hline Group 5 & $A_{5} \rightarrow A_{2}, A_{5} \rightarrow A_{3}, A_{5} \rightarrow A_{4}, A_{5} \rightarrow A_{5}$ \\
\hline
\end{tabular}

\section{Pembobotan}

Pembobotan dilakukan berdasarkan proses relasi fuzzy pada keseluruhan data didalam proses Fuzzyfikasi, sehingga akan diketahui pembobotannya kemudian dimasukkan kedalam matriks yang kemudian akan di normalisasikan, hasilnya seperti tabel berikut:

Tabel 5. Pembobotan

\begin{tabular}{|l|l|l|l|l|l|}
\hline & $A_{1}$ & $A_{2}$ & $A_{3}$ & $A_{4}$ & $A_{5}$ \\
\hline$A_{1}$ & 1 & - & 1 & - & - \\
\hline$A_{2}$ & 1 & - & - & 2 & - \\
\hline$A_{3}$ & - & - & - & - & 2 \\
\hline$A_{4}$ & - & 1 & - & - & 1 \\
\hline$A_{5}$ & - & 1 & 1 & 1 & 1 \\
\hline
\end{tabular}

Tabel 6. Pembobotan Ternormalisasi

\begin{tabular}{|l|l|l|l|l|l|}
\hline & $A_{1}$ & $A_{2}$ & $A_{3}$ & $A_{4}$ & $A_{5}$ \\
\hline$A_{1}$ & $1 / 2$ & - & $1 / 2$ & - & - \\
\hline$A_{2}$ & $1 / 3$ & - & - & $2 / 3$ & - \\
\hline$A_{3}$ & - & - & - & - & $2 / 2$ \\
\hline$A_{4}$ & - & $1 / 2$ & - & - & $1 / 2$ \\
\hline$A_{5}$ & - & $1 / 4$ & $1 / 4$ & $1 / 4$ & $1 / 4$ \\
\hline
\end{tabular}

\section{Menghitung Nilai Peramalan}

Setelah proses pembobotan kemudian menghitung nilai peramalan dengan menggunakan rumus 8 . Perhitungannya seperti berikut ini:

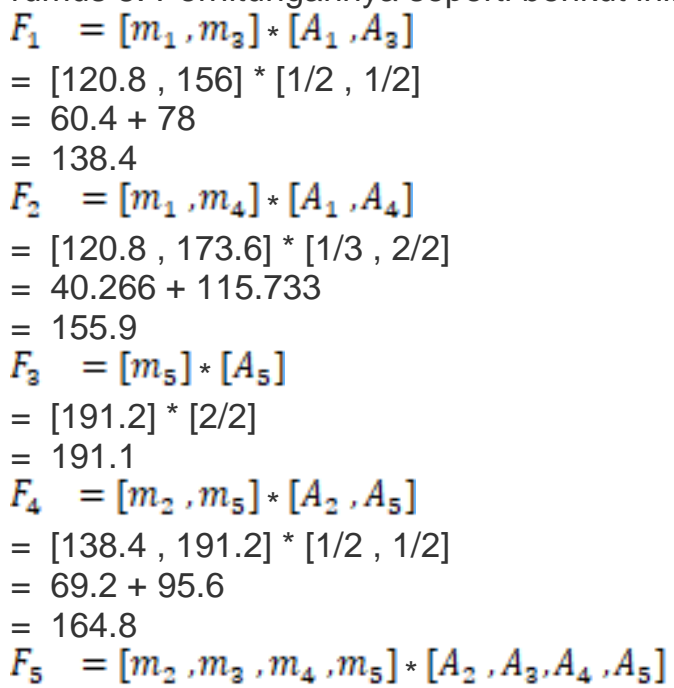


$=[138.4,156,173.6,191.2] *[1 / 4,1 / 4,1 / 4,1 / 4]$

$=34.6+39+43.4+47.8$

$=164.8$

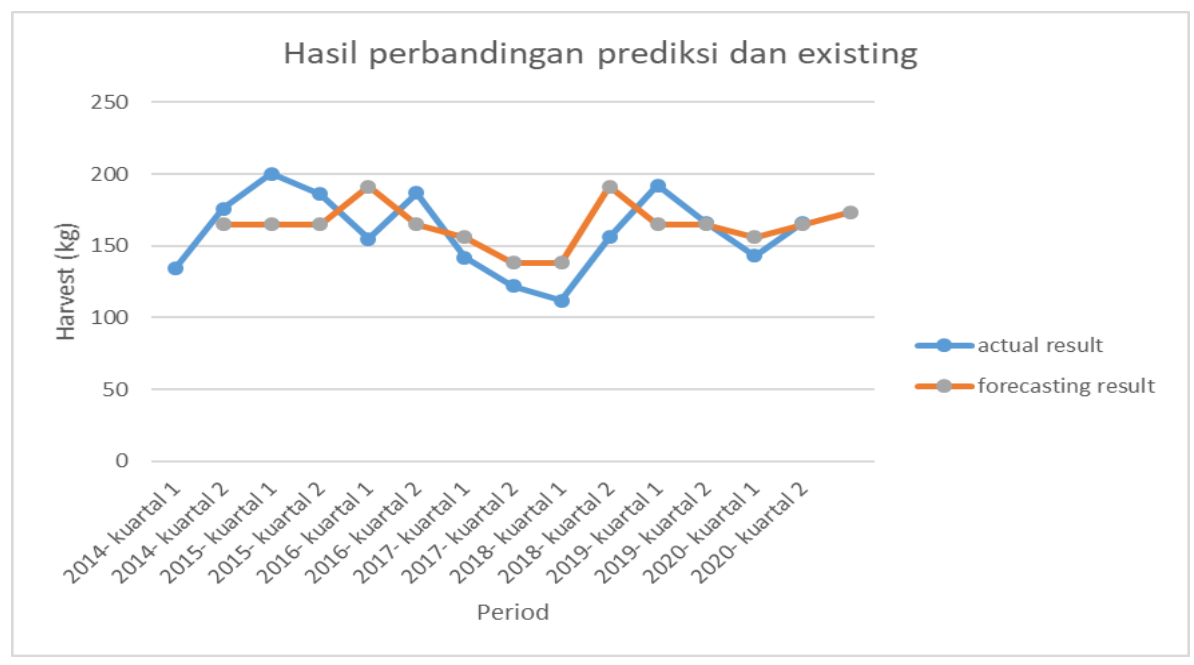

Gambar 1. Grafik Perbandingan Hasil Peramalan

\section{Tingkat Akurasi (MAPE)}

Nilai peramalan yang sudah didapat tersebut diletakkan pada masing-masing himpunan fuzzy serta menghitung nilai error / kesalahan yang dihasilkan menggunakan Algoritma Fuzzy Time Series Model Cheng. Tabel dibawah ini merupakan hasil akurasi MAPE.

Tabel 7. Tabel MAPE

\begin{tabular}{|l|l|l|l|l|}
\hline No. & Periode & Nilai Error & MAPE & Tingkat Akurasi \\
\hline 1 & $2014-$ kuartal 1 & - & - & - \\
\hline 2 & $2014-$ kuartal 2 & 0.063 & $6.3 \%$ & Tinggi \\
\hline 3 & $2015-$ kuartal 1 & 0.176 & $17.6 \%$ & Baik \\
\hline 4 & 2015 - kuartal 2 & 0.113 & $11.3 \%$ & Baik \\
\hline 5 & 2016 - kuartal 1 & 0.233 & $23.3 \%$ & Reasonable \\
\hline 6 & 2016 - kuartal 2 & 0.118 & $11.8 \%$ & Baik \\
\hline 7 & $2017-$ kuartal 1 & 0.097 & $9.7 \%$ & Tinggi \\
\hline 8 & $2017-$ kuartal 2 & 0.134 & $13.4 \%$ & Baik \\
\hline 9 & 2018 - kuartal 1 & 0.235 & $23.5 \%$ & Reasonable \\
\hline 10 & 2018 - kuartal 2 & 0.225 & $22.5 \%$ & Reasonable \\
\hline 11 & $2019-$ kuartal 1 & 0.141 & $14.1 \%$ & Baik \\
\hline 12 & $2019-$ kuartal 2 & 0.007 & $0.7 \%$ & Tinggi \\
\hline 13 & $2020-$ kuartal 1 & 0.090 & $9.0 \%$ & Tinggi \\
\hline 14 & 2020 - kuartal 2 & 0.007 & $0.7 \%$ & Tinggi \\
\hline & Hasil Pramalan & 0.117 & $11.7 \%$ & Baik \\
\hline
\end{tabular}

Dari tabel diatas didapat rata-rata error sebanyak 0.117 dan presentase nilai MAPE sebanyak $11.7 \%$. Dengan demikian dapat disimpulkan tingkat akurasi dari hasil peramalan menggunakan logika fuzzy time series model cheng memiliki tingkat akurasi yang baik.

\section{KESIMPULAN}

Metode fuzzy time series Cheng dapat digunakan sebagai salah satu metode untuk meramalkan hasil panen dari tanaman garut. Berdasarkan hasil peramalan tersebut diperoleh tingkat akurasi MAPE tersebut kurang dari sebesar $11.7 \%$ sehingga dapat disimpulkan bahwa 
peramalan volume hasil panen tanaman garut dengan menggunakan metode fuzzy time series menghasilkan nilai peramalan yang baik.

\section{DAFTAR PUSTAKA}

Chao-HungWang, Predicting tourism demand using fuzzy time series and hybrid grey theory Author links open overlay panel, Tourism Management, Volume 25, Issue 3, June 2004, Pages 367-374

Djaafar, T.F., Sarjiman dan A.B. Pustika. 2010. Pengembangan Budi Daya Tanaman Garut dan Teknologi Pengolahannya untuk Mendukung Ketahanan Pangan. Jurnal Litbang Pertanian, 29(1), 2010.

Susilowati., Endah, W. 2018. Pengaruh Asam Giberelat Dan Ukuran Stek Umbi Terhadap Pertumbuhan Vegetatif Tanaman Garut (Maranta Arundinaceae). Prosiding Seminar Nasional LPPM UPN “Veteran” Yogyakarta.

Gardner, F.P., Pearce, R.B., dan Mitchell, R.I. 1991. Fisiologi Tanaman Budidaya (diterjemahkan oleh Herawati Susilo). UI Press, Jakarta.

Gustriansyah, R. (2017). ANALISIS METODE SINGLE EXPONENTIAL SMOOTHING DENGAN BROWN EXPONENTIAL SMOOTHING PADA STUDI KASUS. 7-12.

Hayati, M. N., \& Wahyuningsih, S. (2017). Peramalan Menggunakan Metode Fuzzy Time Series Cheng Forecasting Using Fuzzy Time Series Cheng Method. Jurnal EKSPONENSIAL, 8, 51-56.

Karasan, A., Sevim, I.., \& Çinar, M. (2017). Fuzzy Time Series. Digital Marketing and Consumer Engagement, VIII(2), 157-190. https://doi.org/10.4018/978-1-5225-5187-4.ch010

Kusumadewi, S., dan Purnomo, H. (2013). Aplikasi Logika Fuzzy untuk Pendukung Keputusan. Yogyakarta: Graha Ilmu.Maharani, N. A. (2018). Implementasi Location Based Service (LBS) Untuk Safety Reporting System Menggunakan Metode A-GPS Dan WIFI Based Indoor Positioning. 28828.

Mey Lista Tauryawati, M Isa Irawan Perbandingan Metode Fuzzy Time Series Cheng dan Metode Box-Jenkins untuk Memprediksi IHSG., JURNAL SAINS DAN SENI POMITS Vol. 3, No. 2, (2014) ISSN: 2337-3539 (2301-9271 Print)

Rakhman, A. Z., Wulandari, H. N., Maheswara, G., \& Kusumadewi, S. (2012). Fuzzy Inference System Dengan Metode Tsukamoto Sebagai Pemberi Saran Pemilihan Konsentrasi ( Studi Kasus : Jurusan Teknik Informatika Uii ), 2012(Snati), 15-16.

Ruey Chin Tsaur, Sunneng Sandino Berutu, Eko Sediyono, Priyo Sidik Sasongko, Peramalan Penjualan dengan Metode Fuzzy Time Series, Jurnal himsya Tech, Vol 11, No 1 (2015)

Ula, M. (2014). Implementasi Logika Fuzzy Dalam Optimasi Jumlah Pengadaan Barang Menggunakan Metode Tsukamoto ( Studi Kasus: Toko Kain My Text ). 1(2). 